\title{
Fabricando prazeres, produzindo dores: o cotidiano conjugal de trabalhadoras com Lesões por Esforços Repetitivos ${ }^{21}$
}

\author{
Regina Lúcia de Souza ${ }^{22}$ e Helerina Aparecida Novo ${ }^{23}$
}

\begin{abstract}
A LER é uma doença do trabalho que tem atingido trabalhadores de ambos os sexos, mais significamente as mulheres. Essa lesão afeta a capacidade funcional, principalmente na realização de atividades profissionais, domésticas e de higiene pessoal. Considerando que em nossa sociedade cabe às mulheres a responsabilidade pelo trabalho doméstico e pelo cuidado dos filhos, essa pesquisa objetivou conhecer as implicações da LER na vida conjugal de mulheres acometidas dessa lesão. Foram entrevistadas seis mulheres, operárias de uma fábrica de chocolates, casadas, com filhos. Utilizamos entrevistas abertas, semi-abertas e questionário. Observamos mudanças na auto-avaliação antes e depois da LER. Verificamos que a perda do trabalho extralar ocasiona grande sofrimento para as entrevistadas. Observamos que, mesmo incapacitadas, as entrevistadas insistem em desempenhar os papéis tradicionais de dona de casa e de mãe e sofrem por não conseguir concretizá-los. Quanto à vida sexual, a lesão não gerou sérios comprometimentos. Apesar de a doença exigir adaptações na vida familiar e conjugal, na percepção das entrevistadas essas interferências não provocaram mudanças no relacionamento afetivo do casal. Concluímos que o fato de a LER interferir na vida de uma mulher casada e com filhos não significa necessariamente que ela tenha relaçôes familiares e conjugais insatisfatórias.

Palavras-chave: Lesões por Esforços Repetitivos, mulher, vida familiar e conjugal.
\end{abstract}

\section{Introdução}

$\mathrm{O}$

interesse pela dimensão psicossocial do relacionamento familiar e conjugal das mulheres com Lesões por Esforços Repetitivos (LER) surgiu durante um estágio realizado no Centro de Referência em Saúde do Trabalhador (CRST) da cidade de Vitória Espírito Santo, no final do ano de 1996.

A organização do trabalho vigente, baseada na lógica do taylorismo, é caracterizada, principalmente, pela cisão entre o planejamento e a execução do trabalho, pela imposição de uma forma padrão de realização que não leva em consideração as diferenças individuais de cada trabalhador (Lima \& Oliveira, 1995), pela pressão da chefia, por exigências de produtividade e ritmo de trabalho acelerado. Também não leva em conta as condições inadequadas de trabalho. Essa forma de trabalhar tem trazido sérias conseqüências à saúde física e mental dos (as) trabalhadores(as). A LER é uma delas.

\footnotetext{
${ }^{21}$ Este artigo é um dos resultados da pesquisa que faz parte da dissertação de mestrado de Souza, R. L. de (2000), Fabricando prazeres, produzindo dores: o cotidiano conjugal de trabalhadoras com Lesões por Esforços Repetitivos (LER), realizada no Programa de Pós-Graduação em Psicologia da Universidade Federal do Espírito Santo.

${ }^{22}$ Mestre em psicologia pelo Programa de Pós-Graduação em Psicologia da Universidade Federal do Espírito Santo.

23 Professora do Programa de Pós-Graduação em Psicologia e do Departamento de Psicologia Social e do Desenvolvimento da Universidade Federal do Espírito Santo.
} 
A LER foi reconhecida no Brasil como doença do trabalho, em 1987, pelo Ministério da Previdência e Assistência Social (MPAS). Em 1991, a Norma Técnica do INSS (Instituto Nacional de Seguridade Social) adotou oficialmente a terminologia Lesões por Esforços Repetitivos - LER (Ministério do Trabalho e da Previdência Social/MTPS, 1991). E, em 1993, utilizou esse termo para denominá-la como:

o conjunto de afecções que podem acometer tendões, sinóvias, músculos, nervos, fáscias e ligamentos, isolada ou associadamente, com ou sem degeneração dos tecidos, atingindo principalmente, porém não somente, membros superiores, região escapular e pescoço, sendo de origem ocupacional e decorrente, de forma combinada ou não, de uso repetitivo de grupo musculares e manutenção de postura inadequada. (Lesões por esforços repetitivos (L.E.R.): Normas técnicas para avaliação da incapacidade, 1993)

Em 1998, entretanto, o INSS publicou uma nova versão dessa norma técnica, que introduz a denominação Distúrbio do Sistema Osteomuscular Relacionado ao Trabalho (DORT), baseado em uma terminologia em inglês - work-related musculoskeletal, em substituição do termo LER. Segundo essa norma, o termo LER não abrange os outros fatores que também podem estar presentes na causalidade, além do esforço repetitivo. Por sua vez, o termo DORT oculta que essa doença ocorre, em grande escala, em trabalhos que exigem esforços repetitivos (Borges, 1999). Por esse motivo e pelo fato de o termo LER ser mais conhecido no Brasil, optamos pelo seu uso neste trabalho.

Hoje, após pouco mais de uma década de seu reconhecimento, segundo vários estudiosos e relatos de dados de atendimentos em Programas de Saúde do Trabalhador, há um consenso em reconhecer que essa doença atinge vários ramos de produção e funções diversificadas de forma veloz, o que a faz ser considerada um grave problema de saúde pública e social (Assunção \& Rocha, 1993; Sato et al., 1993; Codo, 1995; Settimi \& Silvestre, 1995; Ribeiro, 1997).

Até o momento, os estudos que trabalham numa perspectiva psicossocial da LER são unânimes em reconhecer que a principal causa da doença é a organização do trabalho, aqui entendida como sendo "a divisão do trabalho, o conteúdo da tarefa (na medida em que ele dela deriva), o sistema hierárquico, as modalidades de comando, as relações de poder, as questões de responsabilidade etc." (Dejours, 1992, p. 25).

A LER tem atingido trabalhadores de ambos os sexos, jovens, predominantemente aqueles em plena fase produtiva (Settimi \& Silvestre, 1995), com idade abaixo de 35 anos, sendo raro encontrar a doença em trabalhadores com idade acima de 45 anos. No entanto, estudos e relatos contendo informações sobre prestação de serviços aos trabalhadores com LER têm demonstrado que há uma prevalência maior dessa lesão em mulheres (Assunção \& Rocha, 1993; Sato et al., 1993; Settimi \& Silvestre, 1995; Cândido \& Neves, 1998; Ribeiro, 1997). Essa relação mulheres e LER tem gerado uma caracterização indevida, ou seja, a LER tem sido representada como "doença de mulher". Isso baseado em supostas diferenças biológicas ou psicológicas entre homens e mulheres, que contribuem para estabelecer preconceitos e discriminações, além de responsabilizar o (a) próprio (a) trabalhador(a) por seu adoecimento. Existe, porém, um número expressivo de homens com LER e o fato de essa lesão ser conhecida como "doença de mulher" pode estar, de alguma forma, inibindo os homens a revelarem que a adquiriram (Ribeiro, 1997).

Essa lesão afeta a capacidade funcional de trabalhadores e de trabalhadoras, principalmente na realização de atividades profissionais, domésticas e de higiene pessoal. Entretanto, devemos considerar que as diferentes formas de inserção das mulheres e dos homens no mercado de trabalho produzem efeitos diferenciados. Isso se deve ao processo histórico no qual o trabalho é construído, originando em cada época e em cada grupo social, relações de trabalho concretas e específicas para cada gênero que o executa e, conseqüentemente, produzindo sofrimento físico e/ou psicossocial diferenciados. 
Desse modo, considerando que em nossa sociedade cabe às mulheres a responsabilidade pelo trabalho doméstico e pelo cuidado com os filhos, essa pesquisa objetivou conhecer e analisar, a partir das percepções das mulheres com LER entrevistadas, as implicações dessa lesão em suas vidas familiar e conjugal.

\section{Método}

A pesquisa aqui relatada foi um processo de permanente construção. Isso desde o contato com os possíveis participantes até os procedimentos e instrumentos para se ter acesso às histórias. Esse planejamento foi estruturando-se de acordo com que o campo nos oferecia. E ele nos ofereceu muitas dificuldades, muitos obstáculos, fazendo com que reconstruíssemos novos caminhos a cada etapa da coleta dos dados.

A partir de uma pesquisa-piloto realizada com duas mulheres com LER, pacientes do CRST/ES, definimos os critérios para a escolha dos participantes da pesquisa. Estes critérios eram: ser mulher, casada (amasiada), ter filhos e, preferencialmente, apresentar um quadro da doença num grau mais avançado.

Decidimos realizar a pesquisa com trabalhadoras de uma fábrica de chocolates situada no município de Vila Velha/ES, porque tivemos conhecimento do número altíssimo de casos de LER nessa fábrica e da difícil realidade vivida pelas mulheres que ali adquiriram essa lesão.

Esses fatores, juntamente com a possibilidade de conseguir um grupo mais homogêneo em termos de estrato social, já que o nível sócio-econômico da população do CRST/ES era diversificado, além da possibilidade de oferecer às mulheres participantes da pesquisa um espaço de discussão com a formação de um grupo - algo que ali não acontecia, mas já ocorria no CRST/ES com os grupos de "Qualidade de Vida" - foram aspectos decisivos que nos fizeram optar pela realização da pesquisa com as trabalhadoras dessa fábrica. Acreditávamos que mediante a participação no grupo, essas mulheres poderiam elaborar a situação vivida no momento e identificar saídas para melhorar a qualidade de suas vidas (Sato et al., 1993).

Entretanto, apesar do número alto de casos de LER em mulheres na fábrica, despendemos um tempo maior que o previsto para contatá-las e para conseguir realizar as entrevistas. Utilizamos como instrumento inicial para ter acesso às histórias dessas mulheres uma entrevista aberta, de forma que elas pudessem falar livremente sobre suas vidas a partir do surgimento da LER. As entrevistas foram realizadas nas casas das participantes da pesquisa, em dia e horário estabelecidos por elas e tiveram a duração média de 60 minutos.

Utilizamos também um questionário para obter algumas informações básicas sobre a história de cada uma das entrevistadas. Esse questionário foi dividido em três partes. $\mathrm{Na}$ primeira parte, procuramos buscar dados de identificação das entrevistadas. Na segunda, levantamos sua história ocupacional. $\mathrm{Na}$ terceira, abordamos questões relacionadas diretamente com a doença.

Depois dessa entrevista, entramos novamente em contato com cada uma delas, solicitando que confirmassem sua disposição em fazer parte do grupo. Apesar de afirmarem ainda estarem interessadas, houve muitos desencontros nos dias marcados para a reunião. E concluímos que seria inviável insistir na formação desse grupo.

Não contávamos com a possibilidade de não conseguir formar o grupo. Entretanto o inesperado aconteceu e nos fez repensar a estratégia, reformulá-la. Como os métodos usados 
inicialmente foram escolhidos com o intuito de oferecer às participantes da pesquisa um espaço para reflexão e troca de experiências e, a partir das discussões ali geradas, utilizar informações que respondessem aos objetivos do estudo, os dados encontrados por meio das entrevistas individuais e nos questionários pareceram insuficientes para a análise pretendida. Entramos em contato com cada uma delas novamente e marcamos uma nova entrevista. Desta vez, as entrevistas foram semi-estruturadas, enfocando as expectativas das participantes e as de seus companheiros em relação ao casamento, os papéis do marido e da esposa, o lugar da sexualidade na vida do casal; sempre enfatizando suas percepções antes e o depois do surgimento da doença.

Decidimos entrevistar mais uma mulher e novamente encontramos muitas dificuldades. Dessa forma, o total de entrevistadas foram seis, sendo que cinco delas foram entrevistadas em dois momentos distintos e a última, em apenas um encontro.

A análise dos dados obtidos por meio das entrevistas e dos questionários foi realizada com base na técnica de Análise de Conteúdo (Bardin, 1977). Optamos pelo tema como unidade de registro, por considerá-lo o mais adequado na tentativa de buscar o sentido contido nas falas das mulheres participantes da pesquisa em relação à sua vivência com a LER. Para isso, fizemos várias leituras das transcrições da entrevista, retiramos os principais temas que emergiram com mais intensidade na fala das mulheres. Posteriormente organizamos o material, orientando-nos pelas unidades temáticas. Nessa fase, o material foi codificado e foram construídas as relações de interesse.

\section{Resultados}

As mulheres entrevistadas nesta pesquisa, na época das entrevistas, tinham idade entre 27 e 44 anos. Das seis, apenas uma tinha completado o segundo grau, enquanto duas tinham o segundo incompleto e as outras não tinham terminado o primeiro grau. $\mathrm{O}$ tempo de união variava de 6 a 26 anos. Todas tinham dois filhos(as), com idade entre 3 e 22 anos. Quatro dos seis companheiros trabalhavam também nessa fábrica, sendo que um deles estava afastado devido a uma doença do trabalho. Já os outros dois, um era funcionário público e o outro encontrava-se desempregado e fazia bicos, ora pescando, ora tomando conta do bar que possuía na casa onde mora. A renda familiar das entrevistadas girava em torno de 500 e 2.000 reais.

Elas trabalharam na fábrica de chocolates na função de auxiliar de produção ou de operadora, por um tempo que variou de um ano e dez meses a 20 anos. Três encontravam-se afastadas, duas tinham sido demitidas e uma delas tinha sido reintegrada à empresa. No entanto todas, com exceção dessa que foi reintegrada, estavam com algum tipo de processo na Justiça contra a empresa, para serem indenizadas ou para serem reintegradas.

O trabalho de análise de conteúdo permitiu destacar nas falas das entrevistadas seis unidades temáticas: a convivência com a dor e as limitações; auto-imagem; o trabalho remunerado extralar; o trabalho doméstico; a convivência familiar e a convivência conjugal. Apesar das unidades temáticas revelarem um universo rico de informações em relação a essa problemática, abordaremos aqui somente aquelas consideradas mais significativas.

\section{A convivência com a dor e as limitações}

Dor e limites trazem mudanças para a vida cotidiana, mudanças que exigem uma adaptação na relação com marido e filhos. Além de refletirem na forma como as mulheres passam a se perceber como mulheres, como pessoas. 
As entrevistadas expressam uma dificuldade em aceitar que, hoje, depois da LER, elas sejam pessoas com limites físicos.

Porque eu me menosprezava, entendeu? menosprezava, assim, eu não posso fazer isso, não posso fazer aquilo. Eu tenho limitação. (Rosa)

Apesar da maioria revelar ter consciência de seus próprios limites, realizando somente aquelas atividades que percebem que têm condições de fazer, na prática, a maioria, quando se dá conta, já fez algo que não podia e a conseqüência é a dor.

Encontramos entrevistadas que tentam não passar para os seus familiares suas dores, seus sofrimentos, alegando que eles não têm culpa e receando provocar desentendimentos familiares.

\section{Auto-imagem: "Era útil, sou inútil"}

O sofrimento cotidiano das entrevistadas em decorrência da LER reflete-se basicamente na sua auto-imagem e auto-avaliação. Esse aspecto fica evidenciado nas comparações recorrentes entre a sua vida antes e depois da LER.

A maioria das entrevistadas não deixou de comparar o que elas eram antes da LER e o que são hoje, depois do surgimento da doença. Antes de serem acometidas por essa lesão, consideravam-se pessoas que tinham prazer em viver, que gostavam de realizar atividades que parecem ter um aspecto positivo e se autodefinem, nessa época, como pessoas com "alto astral".

Antes da LER eu era mais divertida [risos]. Divertida assim, eu tinha atividades esportivas, eu jogava handebol, entendeu? Eu tinha aquela movimentação, sabe? É aquele prazer pela vida. Gostava de nadar (...). São coisas que depois da LER eu não pude fazer mais(...). Então, quer dizer, ela me privou de muitas coisas boas. (Graça)

Hoje, com a LER, é como se para elas a vida tivesse perdido todo o encantamento que tinha antes, tornando-se pessoas sem muito entusiasmo para viver.

Então, quer dizer, se a gente for parar pra pensar a vida, no caso, a minha vida está assim: ela... parou no tempo, está parada. (Lourdes)

Em relação às expectativas para o futuro, há uma tendência ao conformismo para a maior parte delas. É como se nada mais fosse possível fazer, já que a doença não tem cura.

Em contrapartida, a postura de Sandra em relação ao futuro é um exemplo de que é possível vivenciar a LER de uma outra forma, buscando informações sobre a doença, buscando tratamentos. Ela é a única das entrevistadas que acredita que a sua vida não acabou com a LER. Seus projetos em relação ao futuro refletem a visão de que sempre é possível encontrar novas saídas.

Sandra também é a única entrevistada que, de fato, está tentando dar continuidade à sua vida profissional, buscando outras alternativas através dos estudos.

A minha escrita melhorou, hoje eu consigo escrever bastante, já melhorou muito. E eu estou pensando pro ano que vem eu voltar a estudar. Essa está sendo uma das minhas metas que eu nem imaginava, né? ${ }^{24}$

${ }^{24}$ Quando realizamos a segunda entrevista com Sandra, ela já estava matriculada em uma faculdade e feliz por estar conseguindo estudar. 


\section{O trabalho remunerado extralar}

O trabalho remunerado aparece como algo fundamental para a vida dessas mulheres. O gosto pelo trabalho realizado fora de casa é mencionado direta ou indiretamente em suas falas. Não conseguir realizá-lo causa-lhes muito sofrimento.

Eu... acostumada a fazer tudo, tomar conta de tudo. Tudo que me chamava pra fazer, eu ia. Se eles me chama pra ir pra máquina, eu entro em depressão porque eu não consigo. E era uma coisa que eu gostava: sentar e mandar vê mesmo, trabalhar. Hoje eu não consigo mais. (Lourdes)

Seus salários são percebidos apenas como uma ajuda no orçamento doméstico, mesmo sendo utilizados para o pagamento de despesas essenciais (alimentação, educação, vestuário) ou como um complemento indispensável para a aquisição da casa própria.

Algumas mulheres entrevistadas expressam um grande sofrimento com a perda do seu trabalho remunerado, pois isso vai significar a perda da independência financeira conquistada, ficando difícil depender do dinheiro do marido para atender às suas necessidades pessoais. $O$ trabalho pode representar também uma distração capaz de amenizar a vida cotidiana do casal. Ele possibilita contatos com outras pessoas que não fazem parte do círculo familiar.

Quando você está em casa, assim, que está você e seu marido, é que você vê o que é o casamento. Quando você trabalha e ele trabalha, não. Parece que você se distrai no serviço, sabe? (Carmem)

\section{O trabalho doméstico}

A impossibilidade de realizar os afazeres domésticos aparece como motivo também de grande sofrimento. A limitação da condição física impede ou deveria impedir a realização de todas aquelas atividades que provocam dor, entre elas o trabalho doméstico. No entanto, as entrevistadas insistem em realizá-lo e sofrem por não conseguir fazê-lo de forma eficiente.

Percebemos que as entrevistadas tentam realizar as atividades rotineiras da casa, mesmo sabendo que vai chegar o momento em que a dor será inevitável, porém só deixam de realizá-las quando a dor se torna insuportável. Essas mulheres, apesar de estarem incapacitadas, continuam sendo eternas cuidadoras. Mesmo incapacitadas, sentem-se responsáveis pelo perfeito andamento de tudo aquilo que se refere às atividades do lar. Sob a ótica das relações de gênero, podemos perceber o quanto essa construção social do sexo feminino prejudica as mulheres, no seu olhar para a própria saúde.

Para Dejours (1992), a doença tem implicações diferentes para os homens e para as mulheres. Para eles, a doença leva à paralisação do trabalho; para elas, não, porque elas não podem deixar de cuidar dos filhos e dos afazeres domésticos.

O trabalho doméstico é representado de forma naturalizada. Essa naturalização aparece de diversas formas no discurso das entrevistadas. Algumas mencionam de forma explícita que os afazeres domésticos são atividades comuns à dona de casa, como se não existisse outro jeito: trabalho doméstico, dona de casa é quem tem que fazer.

Encontramos, também, tanto uma representação prazerosa da lida doméstica por parte de algumas, como uma representação desprazerosa da mesma por parte de outras:

... igual eu, assim, que sempre gostei de dar faxina na minha casa, arrumar, você vê e você não poder fazer. (Teresa) 
... tem pessoas que nasceram para serem dona de casa, que não é o meu caso. Não levo muito jeito [risos], não estou acostumada. (Sandra)

Contudo, independente dessa representação, o não cumprimento desse papel da mulher como responsável por cuidar da casa pode gerar sentimentos de inutilidade ou autocobrança:

E em casa, em termos de você não conseguir fazer nada, você se sente inútil, né? (...) Eu até falei com o meu marido, a minha casa está uma vergonha, o banheiro está uma vergonha, tem que limpar e eu não consigo... (Graça)

A necessidade de ajuda na realização do trabalho doméstico passa a ser imprescindível em suas vidas. Essa colaboração provém dos próprios familiares, principalmente daqueles que moram em suas casas ou que moram mais próximos: filhos, marido, irmãs, mãe, nora, sogra, pai.

Em mulheres com uma doença tão incapacitante como a LER e com poucos recursos financeiros, observamos o quanto usufruir de eletrodomésticos é alternativa encontrada para dar conta de cumprir as tarefas domésticas. Apesar das entrevistadas pertencerem a um estrato social no qual as condições financeiras não permitem a compra de todos os eletrodomésticos que poderiam, de fato, facilitar o trabalho da casa, quatro delas citaram terem adquirido, comprando ou ganhando, pelo menos máquina que facilita o trabalho de lavar as roupas.

\section{A convivência familiar}

A LER, para a maioria delas, significou a presença de mais dificuldades em alguns aspectos de seu cotidiano no espaço familiar. Essas dificuldades vão variar em função do momento em que a doença surge e se agrava, da presença de filhos pequenos ou não, do fato da família morar com mais alguém, como uma sobrinha ou nora, por exemplo, se a doença representa a perda ou diminuição do salário da mulher, entre outros aspectos.

Para Lourdes, Rosa e Nívea, a LER trouxe muitas dificuldades para cuidar dos filhos, principalmente na época da amamentação. Já a perda do emprego é a principal causa de dificuldades para duas das entrevistadas. Não poder continuar trabalhando ocasionou dificuldades financeiras que, segundo elas, interferiram na dinâmica familiar.

Pudemos observar que a dor afeta o estado emocional da maioria de nossas entrevistadas. E as famílias tentam amenizar essa dor de alguma forma. Somente Carmem sente que o marido não é solidário com o seu sofrimento. Entretanto, pode contar com o carinho do filho. dor:

Quatro das entrevistadas dizem ser muito difícil lidar com os filhos quando estão com

...só que quando eu sei que eu estou com dor, que eu estou nervosa, eu grito logo: Gente, ó, hoje vocês não me aborrece. (Lourdes)

Algumas entrevistadas encontram, também, formas passivas de agir em relação à doença. Estas formas estão diretamente relacionadas com o controle de seus sentimentos. Nesse sentido, suas ações são de conformar-se com a doença, calar a sua dor.

A reorganização familiar em relação à divisão das tarefas domésticas para a maioria das entrevistadas não gerou problemas. Elas, freqüentemente, ressaltam a compreensão dos 
filhos e do companheiro em realizar o trabalho doméstico. Diante da impossibilidade de a mãe realizar os afazeres domésticos, tende a existir uma divisão de tarefas entre todos os familiares, na maior parte dos casos. Nas freqüentes referências ao fato durante as entrevistas, fica claro que, quando há filhos dos dois sexos, as filhas são as que de fato ficam responsáveis pelo trabalho de casa.

Quando parentes próximos ajudam nas atividades domésticas, a grande maioria cita, principalmente, poder contar com ajuda do sexo feminino, representada pela mãe, irmã, nora, sobrinha, sogra.

Já a participação dos filhos do sexo masculino parece ser esporádica. Quando fazem, é auxiliando a mãe em alguma atividade, mas nem sempre terminam de realizá-la.

Apenas uma das entrevistadas, Sandra, relatou que a experiência de dividir o trabalho doméstico com a família não está sendo algo tranqüilo de ser vivenciado. É uma situação que exige constantemente diálogo, conciliações, readaptações. É difícil porque, como ela nos conta, os filhos reclamam, em alguns momentos, de terem que fazer o trabalho doméstico, atividade que eles não realizavam antes, já que podiam contar com uma empregada ou com a mãe para realizá-la.

Já a experiência de Carmem é diferente. Mesmo com as constantes dores, não pode contar, nem com o marido, nem com os filhos, um rapaz de quinze anos e uma menina de oito para uma divisão dessas atividades. A justificativa? $\mathrm{O}$ marido trabalha durante todo $\mathrm{o}$ dia para buscar o sustento da família; o filho mais velho está na escola pela manhã e trabalha com o pai à tarde; a menina estuda e ainda é muito nova para realizar tais afazeres.

Mesmo impossibilitada e incapacitada para a lida doméstica, a mulher sente-se responsável por essa função. E realiza aquelas que considera essenciais para a família. Teresa, por exemplo, mesmo tendo em casa uma filha de 22 anos e uma nora que fazem todo o trabalho de casa, não deixa de realizar algumas atividades básicas para a família.

Porque a minha função na casa é assim, é cuidar da roupa e da comida. Eu sou mais enjoada, né? (Teresa)

Nas entrevistas, as mulheres mencionam várias vezes o apoio recebido dos filhos, do marido, dos parentes mais próximos, principalmente no que se refere à ajuda nas tarefas domésticas. Elas expressam ser o apoio da família fundamental nessa etapa difícil de suas vidas e acreditam terem tido sorte por estarem sendo compreendidas por eles, desde o início do surgimento da doença.

Essa situação não é válida apenas para Teresa. A fonte principal de apoio relatada por ela vem de amigas que enfrentam o mesmo problema.

Sandra cita, além da ajuda da família, a de alguns profissionais:

... a família tem ajudado muito. E alguns profissionais, que isso aí eu não posso negar. É... psicólogos têm ajudado, acupuntura também, são tratamentos que têm ajudado muito a gente ao longo desse tempo.(...) Realmente questão de apoio eu sempre tive, que foi uma das vantagens. (Sandra)

Esse apoio é descrito de diversas formas: o interesse demonstrado pela família em querer fazer algo para amenizar a dor; a ajuda na realização das tarefas domésticas; a preocupação dos filhos em fazer menos barulho nos momentos da dor; a atitude do marido que sai com os filhos para evitar que a esposa se aborreça ainda mais; o carinho dos filhos, que se aninham na cama da mãe quando percebem que ela está com dor, na tentativa de distraí-la; o incentivo aos seus projetos futuros; a reprovação nos momentos em que insiste 
em fazer algum trabalho de casa que não deveria fazer; ou apenas a manifestação de carinho e aconchego.

\section{A convivência conjugal}

As expectativas das entrevistadas em relação ao casamento, de modo geral, expressam que elas desejam encontrar no relacionamento conjugal a possibilidade de ter alguém com quem possam dividir, compartilhar os momentos negativos e positivos no decorrer de suas vidas, ou seja, esperam encontrar companheirismo.

Quatro das mulheres entrevistadas não fazem nenhuma reclamação a respeito do casamento após o surgimento da LER. Para elas, essa lesão não afetou a vida afetiva do casal. A fala de Rosa é representativa das quatro:

Eu e ele não mudou nada (...) ele é uma pessoa super compreensiva. Por isso não afetou, entendeu? Muito compreensivo mesmo, isso eu não posso reclamar. (Rosa)

Algumas falas tentaram mostrar que, se o casamento não está bom ou se ocorreram mudanças, nem sempre isso está diretamente relacionamento com a LER. As mudanças também ocorreram por outras razões que extrapolam questões relacionadas à lesão.

Por outro lado, a LER pode também gerar mudanças, inclusive mudanças positivas no relacionamento do casal, como Lourdes afirma ter ocorrido em sua vida conjugal:

E eu acho assim depois da LER, no caso, ficou até melhor. Porque [riso]... Nossa! Me ajuda. Aí, eu deito, deixo o pé destapado. Vou puxar a coberta, daí a pouco, está ele me tapando, sabe, me ajeitando, sabe. E eu fico toda molinha assim [risos]. (Lourdes)

Quando as entrevistadas relatam não ter havido mudanças em seus relacionamentos afetivos devido à LER, atribuem ao apoio que encontram nos seus cônjuges. Esse apoio marital, desde o surgimento da doença, é descrito por diversas ações do cônjuge. Por exemplo: o fato dele estar sempre presente nos momentos mais difíceis da doença, como durante as fortes dores. Nessas horas, eles oferecem ajuda, medicando, colocando na cama, fazendo massagens, como já relatamos aqui.

Outro fator que faz com que a LER não atrapalhe o relacionamento dessas entrevistadas com seus cônjuges, segundo elas, é o fato de terem se casado com um homem compreensivo. Ser um marido compreensivo é ser sensível à dor e preocupado com ela, como vimos acima, e tolerante quanto à impossibilidade de cumprimento do papel social que tradicionalmente cabe à mulher.

Assim, todas as entrevistadas, ao avaliarem seus companheiros, consideram-lhes bons maridos. Principalmente porque eles fazem tudo por elas, são compreensivos, bons pais e suprem as necessidades materiais da família.

Com exceção de Carmem, todas as outras entrevistadas descrevem que seus maridos, de uma forma mais habitual ou não, dividem com elas e os filhos a responsabilidade pelo trabalho doméstico. Mas quando averiguamos mais atentamente seus depoimentos, percebemos que uma divisão dos afazeres domésticos de forma justa ou igualitária não existe. O que parece ocorrer é, no máximo, uma ajuda, uma cooperação, principalmente nos momentos de dor mais intensa ou nos momentos em que a esposa, ao estar realizando alguma atividade doméstica, se sente incapaz para terminá-la.

Quanto ao relacionamento sexual do casal, todas elas admitem que a LER interfere na vida sexual do casal. A dor impede que sejam realizadas as mesmas práticas sexuais, exigindo que o casal procure novas alternativas que possibilitem um sexo sem dor. 
Essa interferência diz respeito à freqüência com que fazem sexo e não à sua qualidade e diz respeito também ao fato de o casal precisar encontrar um jeito de fazer sexo sem que haja dor. De certa forma, a LER pode até mesmo trazer mudanças positivas para a vida sexual do casal, pois, para evitar as dores, o casal tem que ser criativo, como relata uma das entrevistadas.

Tende a haver uma preocupação por parte das entrevistadas em atender aos apelos sexuais do marido quando se sentem melhor em relação à doença.

Porque quando tá boa, a gente faz uma graça, né?

A negociação nesse aspecto da vida conjugal torna-se uma necessidade importante para que haja um entendimento entre o casal de forma que a doença não seja motivo para problemas afetivos ou até mesmo separações. As interferências na vida sexual demandam compreensão, diálogo, conciliações, que só são possíveis se a mulher com LER puder contar com um marido compreensivo, que não faça cobranças e respeite os momentos de dores mais intensas, que seja capaz de entender que quando a dor amenizar, sua esposa poderá estar mais disposta também para uma atividade sexual, que é importante para ela a presença dele ali, mais próximo dela. $O$ casal passa a valorizar uma intimidade que não significa necessariamente um interesse na atividade sexual propriamente dita. $\mathrm{O}$ toque, o carinho, a proximidade física são também importantes.

Olha, no meu não. Assim, ele é muito compreensivo, porque nem sempre você está disposta (...). Tem dia que você está em crise, mas tem dia que você está boa, que você pode conversar, a gente conversa muito sobre isso... (Rosa)

... É o que eu falo pra você, meu marido é muito tranqüilo, se eu chego em casa não estou bem, ele vem me procurar, num estou legal, estou com dor, ele deita ali perto de mim, ele vai assistir televisão, eu acabo dormindo. No outro dia ele é a mesma pessoa, entendeu? (Lourdes)

\section{Discussão}

Em primeiro lugar, vale salientar que esta pesquisa é qualitativa e portanto não se pretende generalizar a vivência das entrevistadas desse estudo para todas as mulheres com LER. O que nós pretendemos é conhecer essa realidade dentro do contexto de vida de cada uma delas. Dessa forma, não devemos deixar de considerar que os dados encontrados estão relacionados com mulheres, operárias, de um determinado estrato social. Talvez mulheres de um outro estrato social enfrentariam essa situação de uma outra forma.

As mulheres entrevistadas vivem um "casamento feliz", apesar da LER. Essa imagem de casamento feliz está presente nas falas das entrevistadas. Todas elas enfatizam, de uma forma ou de outra, direta ou indiretamente, que o relacionamento com o marido não mudou em nada depois que adquiriram a LER.

$\mathrm{Na}$ verdade, mudanças aconteceram na forma de o casal se relacionar antes e depois da LER. Práticas antes realizadas no dia-a-dia foram totalmente extintas ou tornaram-se menos intensas, como, por exemplo, a preparação do jantar, a atividade sexual; entretanto, essas mudanças, segundo as entrevistadas, parecem não ter afetado a relação afetiva do casal após a LER. O relacionamento não piorou nem melhorou, isto é, não "mudou nada", segundo suas palavras. Para essas mulheres, o comportamento do marido continua o mesmo de antes do surgimento da LER. Para uma delas, o marido ficou até mais carinhoso com ela. 
Provavelmente, a atenção especial que o marido dispensa a ela devido à lesão faz com que se sinta mais querida, mais amada, fazendo-a perceber que seu casamento mudou para melhor.

Parece que as dificuldades geradas pela lesão não significam necessariamente a criação de mais problemas na vida conjugal, ou seja, a LER pode não ser determinante de problemas conjugais para algumas mulheres afetadas.

$\mathrm{Na}$ literatura brasileira encontrada até o momento sobre este assunto, não se coloca a possibilidade de uma vivência matrimonial sem problemas para mulheres com LER, na percepção das próprias mulheres. O que se observa, de modo geral, é que a vida conjugal e familiar das mulheres com LER significa conflitos e perdas afetivas. Os estudos encontrados no Brasil evidenciam uma visão negativa e problemática relativa ao casamento de uma mulher com LER (Castro et al., 1994; Santorum, 1996; Barreto, 1997).

Entretanto, a literatura internacional na área aponta a possibilidade da convivência conjugal e familiar de mulheres com LER ser percebida de forma mais positiva.

Bammer \& Blignaut (1988), ao realizarem uma revisão bibliográfica sobre o assunto, encontraram um estudo mostrando a possibilidade de existirem mulheres satisfeitas com suas relações familiares, embora acometidas pela doença. Segundo esse estudo, os companheiros têm sido compreensivos e dividem as atividades com suas esposas com LER.

Em nosso estudo, parece que a LER interfere no casamento das entrevistadas e, conseqüentemente, obriga-as a enfrentar dificuldades familiares e conjugais. Contudo, isso não significa, necessariamente, uma convivência insatisfatória nesse âmbito.

Talvez isso ocorra porque, ao avaliarem seus casamentos, essas mulheres consigam perceber, mesmo com todos os problemas decorrentes da LER, um saldo mais positivo que negativo em suas relações conjugais e familiares. Ou seja, as formas encontradas para o casal e os filhos lidarem com as limitações impostas pela lesão e as implicações dela decorrentes fazem com que essas mulheres se sintam bem, satisfeitas com os filhos e o marido ou sintam que é possível continuar convivendo com eles, mesmo que de forma razoável. Nesse sentido, a relação conjugal e familiar não é percebida como insatisfatória.

Entretanto, embora tais formas possam ser encontradas, contribuindo para um saldo positivo nas relações afetivas dentro do casamento, não podemos limitar as experiências de todas mulheres com LER a um único modelo.

Desse modo, é perfeitamente possível que um casal onde a esposa enfrenta uma doença incapacitante como a LER, que exige o redimensionamento de papéis habitualmente cumpridos, possa encontrar por meio do diálogo e de conciliações uma forma mais agradável de interagir. As dificuldades não seriam determinantes de uma relação insatisfatória, podendo até mesmo ocorrer entre eles um relacionamento melhor que o vivido anteriormente, conforme a experiência de uma das nossas entrevistadas.

Neste estudo, o casamento aparece como um "porto seguro" para a grande maioria das mulheres. Isto porque é justamente por meio dele que elas encontram segurança, paz, tranqüilidade para enfrentar as dificuldades e sofrimentos que advêm da LER. Essa segurança, essa paz e essa tranqüilidade estão representadas na figura de um "marido compreensivo".

O que vai sustentar esse casamento sem problemas, apesar da LER, é o fato de as mulheres poderem contar com o privilégio de terem um marido compreensivo, de poder encontrar nele a compreensão de que tanto necessitam para que as interferências ocasionadas pela doença não afetem negativamente o relacionamento do casal.

Indiretamente, algumas entrevistadas revelam alguns deslizes de seus maridos, como companheiros, como pais. Entretanto, parece existir uma tendência entre elas de omitir ou não dar muita atenção ao fato, mesmo que isso abale sua auto-estima. 
Essa postura de não fazer muitas cobranças ao cônjuge para poder conviver e preservar o casamento reafirma o papel da mulher como zeladora do lar. Para manter uma aparente tranqüilidade e a harmonia do casal, evitando dessa forma possíveis desavenças no ambiente familiar, ou para corresponder às expectativas sociais de um casamento feliz, "que está dando certo", a mulher esconde aqueles sentimentos considerados socialmente como negativos. Resigna-se.

Por outro lado, como se queixar dos maridos se eles, além de cumprirem seu papel de provedores do lar, parecem desempenhar aquilo que elas apreenderam, em seu processo de socialização, como papel delas: cuidar? E elas parecem gostar disso. Para a maioria, seus companheiros são bons maridos porque também se preocupam com elas, cuidam delas como uma mãe cuida de um filho doente, ou seja, dão banho (em alguns casos), colocam-nas na cama, alimentam-nas, medicam-nas. Fazem de tudo por elas, como diz Graça:

...só não dá o céu porque ele não pode.

Os maridos dessas mulheres com LER passam, então, a exercer um papel de protetor. Nesse caso a mulher "cuidadora do outro" passa a ser "cuidada pelo outro". E essa experiência parece ser vista de forma positiva, tanto que é idealizada por aquelas que não a vivenciam. A mulher, numa situação rara, pode então estar do outro lado, ou seja, ser cuidada, ao invés de cuidar, um trabalho que sempre realizou. Entretanto essas mulheres continuam sendo as principais responsáveis pelos cuidados dispensados ao lar.

Essa idealização do marido talvez seja uma das razões que levam as entrevistadas a perceberem a vida sexual como não problemática. Tendo que conviver constantemente com dores e limitações físicas, ter um companheiro que cuide delas, que as ajude na criação dos filhos e nas tarefas da casa parece ser o que mais importa. $O$ sexo, então, pode passar a ocupar um lugar secundário em suas vidas. E mesmo que sua vivência seja problemática, melhor não pensar ou questionar, pois isso pode levar a muitos outros problemas e conflitos entre o casal, inclusive a perda do marido, o que poderia ser ainda mais difícil para elas.

Esses achados que mostram que a LER não comprometeu a vida sexual do casal diferem dos encontrados na literatura, os quais registram sérios comprometimentos na vida sexual de mulheres com LER (Castro et al., 1994; Colbari, 1995; Santorum, 1996; Barreto, 1997; Oliveira, 1999). Acreditamos que os dois casos possam ocorrer, que até mesmo haja casos em que justamente o sexo possa propiciar um maior entendimento para o casal, isto é, em que o sexo seja a via possível para o casal contornar possíveis problemas decorrentes da lesão.

As diferenças encontradas entre esse estudo e os demais, em relação à vida conjugal de mulheres com LER merece uma reflexão mais aprofundada a ser trabalhada em um outro momento. Entretanto, cabe registrar algumas de nossas impressões iniciais. Todos eles utilizaram uma metodologia qualitativa, não parecendo haver diferenças metodológicas significativas, entretanto no nosso estudo a vida familiar e conjugal das mulheres com LER era o objetivo central, enquanto nos outros essa temática era uma entre as outras abordadas ou um dado encontrado, possibilitando ao primeiro um acesso mais detalhado das suas histórias. Quanto aos sujeitos das pesquisas, não encontramos especificidades entre eles, em termos de estrato social, escolaridade, grau da lesão, participação em algum trabalho psicológico ou de orientação relacionado à LER que pudessem explicar essas diferenças. Por outro lado, questionamos se elas não estão relacionadas simplesmente com a forma singular como cada um deles vivencia essa lesão em suas vidas. E no nosso estudo, especificamente, as entrevistadas vivenciam de uma forma mais positiva.

"Casamento feliz", "marido compreensivo" e "sexo sem problemas" são imagens positivas que nossas entrevistadas relataram ao longo da investigação. Para a maioria delas, 
superar as dificuldades decorrentes da LER só é possível porque podem encontrar no marido e nos filhos o apoio, o respeito, a compreensão que necessitam para continuar levando a vida apesar das dificuldades decorrentes da LER.

\section{Considerações finais}

Extrair de nossas entrevistas o cotidiano familiar e conjugal antes e depois da LER não foi uma tarefa fácil. A maior parte de nossas conversas, com todas as entrevistadas sem exceção, era sobre as vivências relativas ao trabalho, mesmo sendo explicitado desde o início o nosso interesse em conhecer as interferências da LER na vida conjugal e familiar de cada uma delas.

Neste trabalho, mais que agrupar semelhanças, tentamos mostrar as diversidades existentes em cada vivência. E isso foi um grande desafio. Situações comuns diante da LER foram encontradas, porém procuramos estar sempre atentos para a possibilidade de encontrar vivências diferentes, para não se correr o risco de generalizar a convivência conjugal de mulheres com LER. Nesse sentido, cada uma de nossas entrevistadas vivencia a LER em suas vidas de uma forma singular, conforme suas histórias pessoais e o contexto social em que vivem.

Temos a tendência de, muitas vezes, erroneamente, acreditar apenas em uma única possibilidade de vida para determinados tipos de situação. Antes de ir a campo, não acreditávamos que uma mulher com LER, casada, com filhos, pudesse estar se sentindo bem com sua vida familiar e conjugal. Esperávamos encontrar mulheres infelizes, desiludidas com seus companheiros. Para nossa surpresa, a realidade encontrada foi oposta às nossas expectativas. E foi muito difícil para nós aceitarmos isso. Duvidávamos, questionávamos uma realidade colhida por nós.

Essa situação de pesquisa vivenciada por nós remete-nos ao preconceito do próprio pesquisador em relação à realidade que é estudada por ele, podendo esse preconceito deturpar a real vivência de nossos sujeitos. Os pesquisadores, principalmente os iniciantes, devem estar sempre atentos para este risco.

A pesquisa mostrou as formas diferentes com que as mulheres entrevistadas se manifestam sobre sua vivência com LER. Encontramos um grupo que acredita que nada pode fazer para melhorar ou para sair da situação de sofrimento em que vivem, enquanto somente uma delas está conseguindo dar um salto qualitativo em sua vida. As primeiras vivem seus sofrimentos isoladamente, são pouco informadas e pouco dispostas a buscar informações sobre a doença que têm. Por outro lado, a que se diferencia dessas, além de estar em processo contínuo de informação sobre sua doença, vivencia seu sofrimento compartilhando-o com outras pessoas que passam por situação semelhante à sua, isto é, ouve, discute e reflete sobre experiências parecidas e diferentes das que vive.

O que se pretende enfatizar é a importância de se criar oportunidades para que a LER seja vivenciada coletivamente, para que as várias formas que cada um encontra de lidar com ela possam ser conhecidas, discutidas, refletidas por aquelas pessoas que a possuem. Elas são os "especialistas" da sua própria doença e podem juntas, unidas, encontrar saídas positivas que amenizem seus sofrimentos. Saídas não só ao nível da atuação individual, mas também no coletivo, abrangendo ações de prevenção, de reivindicação de direitos e benefícios sociais, entre outras que contribuam com a melhoria da situação geral dos(as) trabalhadores(as) com LER. Não se quer com isto negar o conhecimento médico, mas colaborar para que o sofrimento seja vivenciado de tal forma 
que potencialize as pessoas para a vida pessoal e coletiva, assim como foi possível observar na experiência de Sandra.

Apesar das dificuldades encontradas para produzir um conhecimento que retrate o outro lado das vivências de mulheres com LER, além daquele relativo ao trabalho, ou seja, o seu cotidiano familiar e conjugal, acreditamos que nós, como psicólogos sociais, nas palavras de Sawaia (1999, p. 113), "precisamos continuar pesquisando para conhecer os sentidos que os sujeitos dão a suas experiências, os comportamentos que adotam em relação a si e aos outros e os sentimentos vivenciados no processo".

\begin{abstract}
Conjugal routine of women workers with repetitive strain injury
The RSI is a work illness that has affected both sexes, but mostly women. This injury affects functional capacities, mainly in the execution of professional activities, household chores and personal hygiene. Considering that in our society women are responsible for performing household chores and taking care of children, this research had the purpose to find out conjugal routine problems in women with RSI. Six married women with children were interviewed. They were manual workers of a chocolate factory. We used opened and semi-opened interviews and questionnaire and observed changes in their self-evaluation before and after RSI. We noticed that, being away from their jobs, caused great suffering to them. We observed that, in spite of not being able to, they insisted on doing traditional housework and suffered for not accomplishing it. As far as their sexual life, the injury did not cause serious damage. Although the illness requires adaptation in family and conjugal life, the women interviewed thought that did not affect their emotional relationship. We concluded that RSI interference in the lives of married women with children does not, necessarily, mean they have unsatisfactory family and spouse relationships.
\end{abstract}

Keywords: Repetitive Strain Injure, women, conjugal routine.

Endereços para contato com as autoras:

Regina Lúcia de Souza: reginals@uai.com.br

Helerina Aparecida Novo: hnovo@zaz.com.br

Manuscrito recebido em: 01/02/01

Aprovado para publicação em: 13/09/01

\title{
Referências
}

Assunção, A. A. \& Rocha, L. (1993). E Agora... até namorar fica difícil: uma história de lesões por esforços repetitivos. In L. E. Rocha, R. M. Rigotto \& J.T.P. Buschinelli (Orgs.), Isto é trabalho de gente? Vida, doença e trabalho no Brasil (pp. 461-493). São Paulo: Vozes.

Bammer, G. \& Blignault, I. (1988). More than a pain in the arms: a review of the consequences of developing occupational overuse syndromes. Journal Occupational Health Safety, Austrália, 5 (4), 389-397.

Bardin, L. (1977). Análise de conteúdo. Lisboa: Edições 70. 
Barreto, M. (1997). Lesões por esforços repetitivos (L.E.R.): que danos causam no cotidiano das mulheres. In A.C.P. Brêtas (Org.), Trabalho, saúde e gênero: na era da globalização (pp. 461-493). Goiânia: AB.

Borges, L.H. (1999). Sociabilidade, sofrimento psíquico e lesões por esforços repetitivos em processos de trabalhos repetitivos: estudo de caixas bancários. Tese de Doutorado, Instituto de Psiquiatria, Universidade Federal do Rio de Janeiro, Rio de Janeiro.

Cândido, V. G. \& Neves, M. de A. G. (1998). Trabalho e saúde: um estudo de caso da L.E.R. numa empresa do setor metalúrgico. In M.E.A. Lima, J. N. de A. Garcia \& F. de P. A. Lima (Orgs.), LER dimensões ergonômicas e psicossociais (pp. 181-200). Belo Horizonte: Health.

Castro, A. L. de, Faria, M.M., Adorno, R. C. F. \& Zioni, F. (1994). Mulher, muler: saúde, trabalho, cotidiano. In P. C. Alves \& M. C. de S. Minayo (Orgs.), Saúde e doença: um olhar antropológico (pp. 141- 52). Rio de Janeiro: Fiocruz.

Codo, W. (1995). Providências na organização do trabalho para a prevenção da LER. In W. Codo \& M.C.C.G. Almeida (Org.), LER diagnóstico, prevenção e tratamento: uma abordagem interdisciplinar (pp. 222-48). Petrópolis: Vozes.

Colbari, A.L. (1995). Ética do trabalho. São Paulo: Letras \& Letras, UFES.

Dejours, C. (1992). A loucura do trabalho: estudo de psicopatologia do trabalho (A. I. Paraguay \& L. L. Ferreira, trad., 5ª ed. ampliada). São Paulo: Cortez-Oboré.

Lesões por Esforços repetitivos (L.E.R.): Normas técnicas para avaliação da incapacidade. (1991). Brasília: Ministério da Previdência e Assistência Social.

Lesões por esforços repetitivos (L.E.R.): Normas técnicas para avaliação da incapacidade. (1993). Brasília: Ministério da Previdência e Assistência Social.

Lima, A. B. \& Oliveira, F. de. (1995). Abordagem psicossocial da L.E.R.: Ideologia da culpabilização e grupos de qualidade de vida. In W. Codo \& M. C. C. G. Almeida (Orgs.), LER diagnóstico, tratamento e prevenção (pp. 136-59). Petrópolis: Vozes.

Oliveira, E. M. de. (1999). A mulher, a sexualidade e o trabalho. São Paulo: Hucitec.

Ribeiro, H. P. (1997). LER: conhecimento, práticas e movimentos sociais. São Paulo: FSP-USP/ SSE-SP.

Santorum, K. M. T. (1996). Mulheres trabalhadoras e Lesões por Esforços Repetitivos: uma análise na perspectiva de gênero e trabalho. Dissertação de Mestrado, Instituto de Psicologia, Pontifícia Universidade Católica do Rio Grande do Sul, Rio Grande do Sul.

Sato, L., Araújo, M. D. \& Franco, M. A. J. (1993). Atividade em grupo com portadores de LER e achados sobre a dimensão psicossocial. Revista Brasileira de Saúde Ocupacional, 21 (79), 49-62.

Sawaia, B. B. (1999). O sofrimento ético-político como categoria de análise da dialética exclusão-inclusão. In B. B. Sawaia (Org.), As artimanhas da exclusão: análise psicossocial e ética da desigualdade social (pp. 96-116). Petrópolis: Vozes.

Settimi, M.M. \& Silvestre, M. P. (1995). Lesões por esforços repetitivos (LER): um problema da sociedade brasileira. In W. Codo \& M.C.C.G. Almeida, (Orgs.), LER: diagnóstico, tratamento e prevenção (pp. 321-51). Petrópolis: Vozes. 